\title{
Design and experimental study of a planetary gearing mechanism based on twice unequal amplitude transmission ratio
}

\author{
J iangang Liu ${ }^{1,2}$, Gaohong $\mathrm{Yu}^{1,3^{*}}$, Zhipeng Tong ${ }^{1,3}$, Yao Hua ${ }^{1,3}$ \\ (1. School of Mechanical Engineering \& Automation, Zhejiang Sci-Tech University, Hangzhou 310018, China; \\ 2. College of Mechanical and Electrical Engineering, Wuyi University, Wuyishan 354300, Fujian, China; \\ 3. Zhejiang Province Key Laboratory of Transplanting Equipment and Technology, Hangzhou 310018, China)
}

\begin{abstract}
To obtain the optimal seedling taking trajectory, this study proposed the adjustment of the total transmission ratio curve by using human-computer interaction. On the basis of this design method, a planetary non-circular gear mechanism was designed that can realize the twice unequal amplitude transmission ratio to meet the seedling harvesting requirements. The cubic non-uniform B-spline curve was used to fit the twice unequal amplitude transmission ratio curve, and the transmission ratio was freely distributed in two levels. The seedling pick-up mechanism was designed by controlling the seedling taking track and the corresponding attitude directly through the local section of the total transmission ratio, and the gear pitch curve was directly controlled by the transmission ratio. The kinematics model of the seedling pick-up mechanism was also established. Furthermore, the influence of the total transmission ratio on the seedling picking track, the ratio of the wave crest to the amplitude, and the mechanism parameters were discussed. A human-computer interactive optimization software was developed using Matlab, and a set of optimal parameters for the seedling pick-up mechanism was obtained to meet the transplanting requirements. By using the Adams software, the virtual prototype simulation of the seedling pick-up mechanism was completed, and the idle experiment for the track and attitude of the prototype was conducted through high-speed camera technology. The theoretical, simulated, and experimental trajectories were consistent with each other. Results revealed that the success rate of the seedling picking exceeded $90 \%$ when the rotation speeds were $40 \mathrm{r} / \mathrm{min}, 50 \mathrm{r} / \mathrm{min}$, and $60 \mathrm{r} / \mathrm{min}$, and the qualified rate of the matrix decreased with the increase in rotating speed. Moreover, the number of damaged plants increased with the increase in rotating speed. The experimental results showed that the seedling pick-up mechanism designed using the proposed method demonstrated a good effect and met the required seedling picking performance.
\end{abstract}

Keywords: seedling pick-up mechanism, second unequal amplitude, planetary gear train, seedling picking experiment DOI: $10.25165 /$ j.ijabe. 20221501.6168

Citation: Liu J G, Yu G H, Tong Z P, Hua Y. Design and experimental study of a planetary gearing mechanism based on twice unequal amplitude transmission ratio. Int J Agric \& Biol Eng, 2022; 15(1): 155-163.

\section{Introduction}

Mechanical transplanting can overcome the problem of crops not being continuously planted due to seasonal limitations. Using seedling transplanting technology can help mitigate the effect of seasons on crops, ensure the consistency and stability of crop growth with the same conditions and development, improve the land utilization rate, and increase the cropping index ${ }^{[1,2]}$. The performance of the seedling pick-up mechanism is the key to realizing fully automated transplanting. This mechanism is also the core component of an automatic vegetable transplanter. Therefore, the establishment of a reasonable structure, stable performance, and high efficiency of the seedling pick-up mechanism is the premise for realizing the automation of vegetable production $^{[3-5]}$.

Received date: $2020-09-18 \quad$ Accepted date: 2021-03-17

Biographies: Jiangang Liu, $\mathrm{PhD}$ candidate, research interest: agricultural machinery design, Email: 201910501012@mails.zstu.edu.cn; Zhipeng Tong, $\mathrm{PhD}$ candidate, research interest: agricultural machinery design, Email: 201420501046@mail.zstu.edu.cn; Yao Hua, MS, research interest: agricultural machinery design, Email: 314441626@qq.com.

*Corresponding author: Gaohong $\mathrm{Yu}, \mathrm{PhD}$, Professor, research interest: agricultural machinery design. Faculty of Mechanical Engineering and Automation, Zhejiang Sci-Tech University, Hangzhou 310018, China. Tel: +86-13093730475, Email: yugh@zstu.edu.cn.
Choi et al. ${ }^{[6]}$ from South Korea designed a five-bar seedling pick-up mechanism for potted vegetable seedlings. The mechanism is fixed on the frame by a sliding tool. The crank rotates counterclockwise around the rotation center to drive the slide block, and the slide block reciprocates in the slide way to drive the guide bar mechanism to complete the process of seedling picking and pushing. However, this mechanism has several issues, such as the wear of the slide way and incompatibility of single-arm seedling picking for high-speed applications. The obtained seedling picking efficiency is lower than 40 plants $/ \mathrm{min}$. Moreover, implementing continuous improvement to this mechanism is difficult. Ashutosh et al. ${ }^{[7]}$ from India developed a six-row semi-automatic transplanter that requires one person to feed the seedlings manually in each row. As a result, the obtained working efficiency is low. Iqbal ${ }^{[8]}$ from South Korea developed a single-arm seedling pick-up mechanism with a connecting rod, which collects seedlings by installing a clamping-type needle on the single arm. However, this tool has a slow speed and low efficiency and is difficult to improve. Ktsugar ${ }^{[9]}$ designed an automatic vegetable transplanter by using a gear train and a connecting rod slide. However, the transplanting efficiency is only 50 plants $/ \mathrm{min}$, and the slide is easily damaged. Shaw ${ }^{[10,11]}$ in the United States developed an ejection-type seedling pick-up mechanism which used a pneumatic ejector to push out plug seedlings and coordinated with belt conveyor and spatial link 
mechanism to realize tomato and pepper plug seedling transplanting with high transplanting efficiency and success ratio. Kang et al. ${ }^{[12]}$ from South Korea developed a two-row vegetable transplanter with a fork-type seedling picking device, and the plant shortage rate of the transplanter was $13.7 \%$. Thomas ${ }^{[13]}$ from India developed a four-row rice transplanter with a planar four-bar mechanism, and verified it by experiment. Kumar ${ }^{[14]}$ from India developed a $9.75 \mathrm{~kW}$ walking tractor-driven two-line automatic potted seedling transplanter. The transplanter adopts a horizontal slat chain for conveying and a horizontal pusher chain machine for conveying. The planting rate is 32 pots $/ \mathrm{min}$ and the missing planting rate is $4 \%$.

In China, it is not long to study automatic seedling pick-up Mechanism. Xin et al. ${ }^{[15]}$ designed a rice transplanting mechanism based on elliptical gear and double crank five-bar mechanism. The transplanting efficiency is 200 plants $/ \mathrm{min}$. This method is suitable for transplanting rice with an " 8 " shaped seedling track but not for transplanting potted vegetable seedlings. Han et al. ${ }^{[16]}$ designed a clamp-type seedling pick-up mechanism consisting of an oscillating guide linkage mechanism and a grooved globoidal cam mechanism. Yu et al. ${ }^{[17]}$ used mechatronics technology (e.g., single-chip microcomputer, solenoid valve, and cylinder) to complete the transplanting action. Mao et al. ${ }^{[18]}$ designed a gate-shaped seedling pick-up mechanism, which is mainly composed of a crank gate-shaped guide rod, a track actuator with a cam profiling chute, a seedling picking claw mechanism, and a cam mechanism (to control the opening and closing of the seedling picking claw). The picking speed is 40-70 r/min. However, the seedling picking claw cannot entirely hold the bowl body. Moreover, the mechanism is a cam slider mechanism, which is not suitable for high-speed operation because its seedling picking speed cannot be improved. Yin et al. ${ }^{[19]}$ used two sections of seedling picking track to synthesize the seedling picking section track and designed a vegetable bowl seedling taking mechanism through the inverse analysis of the node curve shape by considering the seedling track. The experiment is performed using big chili plug seedlings. Although the seedling picking performance is satisfactory, the agreement between the experimental and theoretical trajectories is not ideal. Dang et al. ${ }^{[20]}$ designed a single-degree-of-freedom open-hinge four-bar mechanism. However, the slide easily wears and therefore affects the seedling picking accuracy. Liu et al. ${ }^{[21]}$ investigated the damage rate of the seedling lump when using flat and round needles via X-ray to detect the seedling lump during the clamping state. They concluded that the minimum damage rate of the seedling lump occurs when the diameter of the round needle is $2 \mathrm{~mm}$. This method presents a guiding significance for the design of the seedling picking needle. Yuan et al. ${ }^{[22]}$ designed a compound air blowing-vibration seedling pick-up mechanism (i.e., a seedling pick-up mechanism that combines vibration and air blowing), which is mainly composed of a seedling delivery device, a vibration device, and an air blowing device. However, this mechanism has a low success rate, high energy consumption, and a high damage rate of the potted seedling matrix. Jia et al. ${ }^{[23]}$ proposed a seedling pick-up mechanism with a cam-connecting rod. This mechanism achieves low seedling picking efficiency and is difficult to improve. Yu et al. ${ }^{[24-26]}$ designed a seedling pick-up mechanism consisting of a planetary gear train with an incomplete combined non-circular gear. The design method is to use the non-circular planetary gear train to realize specific seedling picking tracks and postures. The design parameters of this mechanism vary, and the concave and convex parts are adjusted through trial and error and repeated experiments; such approaches are difficult to optimize, work-intensive, and inefficient.

In the present study, this research proposed a design method that used the type value point of the total transmission ratio to directly adjust the seedling path and designed a non-circular planetary gear train mechanism that could realize the twice unequal amplitude transmission ratio and the direct control of the pitch curve shape of the non-circular gear by dividing such ratio. By analyzing the influence of the total transmission ratio, sub-transmission ratio, peak value of the transmission ratio, and mechanism parameters on the seedling picking track, a group of parameters for the seedling picking mechanism that satisfied the working requirements through human-computer interaction were obtained. The simulation analysis of the seedling pick-up mechanism was performed using Adams software. The prototype produced using the seedling pick-up mechanism was verified through experiments.

\section{Mechanism composition and working principle}

Figure 1 shows the schematic of the twice unequal amplitude transmission ratio of the seedling pick-up mechanism of the planetary gear train. The non-circular sun gear is fixed on the frame and meshes with the non-circular first intermediate gears. The non-circular second intermediate gears meshes with the non-circular planet gears. The two intermediate gears, as well as the seedling arm and planetary gears, are fixed to each other. The planet carrier rotates counterclockwise around point $\mathrm{O}_{1}$ and drives the first and second intermediate gears and the planetary gears to rotate around $\mathrm{O}_{2} / \mathrm{O}_{2}{ }^{\prime}$ and $\mathrm{O}_{3} / \mathrm{O}_{3}{ }^{\prime}$, respectively, while engaging and driving. The two arms take the seedlings twice along the path in one cycle. The bowl is generally positioned at an angle of $45^{\circ}$. The seedling picking arm completes the seedling picking, holding, and pushing processes in tracks A-B-C, C-D, and D-E, respectively. The seedling picking arm completes one cycle of the seedling picking process and returns to prepare the next cycle in track E-A.

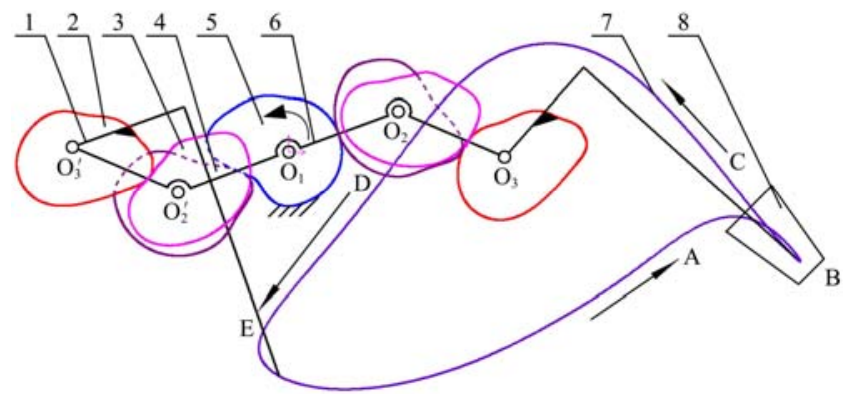

1. Seedling arm 2. Planetary gear 3. Second intermediate gear 4. First intermediate gear 5. Sun gear 6. Planet carrier 7. Seedling track 8. Bowl plate

Figure 1 Schematic of the secondary non-circular gear-drive seedling pick-up mechanism with unequal amplitude

\section{Kinematics analysis of the seedling pick-up mechanism}

Figure 2 shows the initial installation position of the seedling pick-up mechanism, and Table 1 lists the parameters required for modeling the mechanism to facilitate kinematic modeling.

Given the angle of the sun gear and transmission ratio, the angles of the first and second intermediate gears and planetary gear and the pitch curve models can be obtained based on the gear meshing principle. 


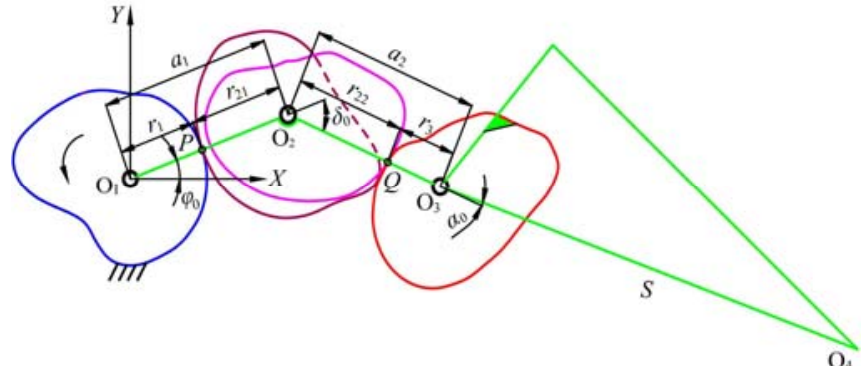

Figure 2 Initial installation position of the seedling pick-up mechanism

Table 1 Parameters for the seedling pick-up mechanism

\begin{tabular}{|c|c|}
\hline Symbol & Meaning \\
\hline $\mathrm{O}_{1}$ & Rotation epicenter of the planet shelf \\
\hline $\mathrm{O}_{2}$ & Center of the rotation of the intermediate gear \\
\hline $\mathrm{O}_{3}$ & Rotation epicenter of the planet gear \\
\hline $\mathrm{O}_{4}$ & Needle point of arm seedling \\
\hline$P$ & First gear engagement point \\
\hline$Q$ & Second stage gear engagement point \\
\hline$a_{1} / \mathrm{mm}$ & Distance of the center of the first gear \\
\hline$a_{2} / \mathrm{mm}$ & Centre distance of the second stage gear \\
\hline$\varphi_{1} / \mathrm{rad}$ & Angle of the planet carrier \\
\hline$S / \mathrm{mm}$ & $\begin{array}{l}\text { Distance from the rotation center of the planet gear to the tip of } \\
\text { the seedling needle }\end{array}$ \\
\hline$r_{1} / \mathrm{mm}$ & Engagement radius of the sun gear \\
\hline$r_{21} / \mathrm{mm}$ & Engagement radius of the first intermediate gear \\
\hline$r_{22} / \mathrm{mm}$ & Engagement radius of the second intermediate gear \\
\hline$r_{3} / \mathrm{mm}$ & Engagement radius of the planetary gear \\
\hline$\varphi_{0} / \mathrm{rad}$ & Initial installation position of the planet carrier \\
\hline$\alpha_{0} / \mathrm{rad}$ & $\begin{array}{l}\text { Installation position of the seedling taking arm relative to the } \\
\text { planet carrier }\end{array}$ \\
\hline$\delta_{0} / \mathrm{rad}$ & $\begin{array}{l}\text { Angle of rotation of the second-stage planetary carrier relative to } \\
\text { the first-stage planetary carrier }\end{array}$ \\
\hline$\phi_{\mathrm{j}} / \mathrm{rad}$ & jth value point that corresponds to the planet carrier angle \\
\hline
\end{tabular}

The $\mathrm{O}_{2}$ displacement can be expressed as

$$
\left\{\begin{array}{l}
x_{\mathrm{O}_{2}}(k)=a_{1} \cos \left(\varphi_{0}+\varphi_{1}(k)\right) \\
y_{\mathrm{O}_{2}}(k)=a_{1} \sin \left(\varphi_{0}+\varphi_{1}(k)\right)
\end{array},(k=1, \ldots, n)\right.
$$

The $\mathrm{O}_{3}$ displacement can be written as

$\left\{\begin{array}{c}x_{\mathrm{O}_{3}}(k)=a_{1} \cos \left(\varphi_{0}+\varphi_{1}(k)\right)+a_{2} \cos \left(\varphi_{0}+\delta_{0}+\varphi_{1}(k)\right) \\ y_{\mathrm{O}_{3}}(k)=a_{1} \sin \left(\varphi_{0}+\varphi_{1}(k)\right)+a_{2} \sin \left(\varphi_{0}+\delta_{0}+\varphi_{1}(k)\right)\end{array},(k=1, \ldots, n)\right.$

The $\mathrm{O}_{4}$ displacement can be defined as

$$
\left\{\begin{array}{l}
x_{\mathrm{O}_{4}}(k)=x_{\mathrm{O}_{3}}(k)+S \cos \left(\varphi_{0}+\delta_{0}+\varphi_{1}(k)+\alpha_{0}\right) \\
\mathrm{y}_{\mathrm{O}_{4}}(k)=y_{\mathrm{O}_{3}}(k)+S \sin \left(\varphi_{0}+\delta_{0}+\varphi_{1}(k)+\alpha_{0}\right)
\end{array},(k=1, \ldots, n)\right.
$$

Given that the planet carrier rotates counterclockwise around the rotation center at a constant angular velocity, command $t=\pi / 180 / \omega$. The relative angular velocities of the intermediate and planetary gears are shown by Equations (4)-(6).

$\mathrm{O}_{2}$ velocity:

$$
\left\{\begin{array}{l}
\dot{x_{\mathrm{O}_{2}}}(k)=-a_{1} \omega \sin \left(\varphi_{0}+\varphi_{1}(k)\right) \\
\dot{y_{\mathrm{O}_{2}}}(k)=-a_{1} \omega \cos \left(\varphi_{0}+\varphi_{1}(k)\right)
\end{array},(k=1, \ldots, n)\right.
$$

$\mathrm{O}_{3}$ velocity:

$$
\left\{\begin{array}{c}
\dot{x_{\mathrm{O}_{3}}}(k)=-a_{1} \omega \sin \left(\varphi_{0}+\varphi_{1}(k)\right)-a_{2} \omega \sin \left(\varphi_{0}+\delta_{0}+\varphi_{1}(k)\right) \\
\dot{y_{\mathrm{O}_{3}}}(k)=-a_{1} \omega \cos \left(\varphi_{0}+\varphi_{1}(k)\right)+a_{2} \omega \cos \left(\varphi_{0}+\delta_{0}+\varphi_{1}(k)\right) \\
(k=1, \ldots, n)
\end{array}\right. \text {, }
$$

$\mathrm{O}_{4}$ velocity:

$$
\left\{\begin{array}{l}
\dot{x_{O_{4}}}(k)=\dot{x_{O_{3}}}(k)+S \omega \sin \left(\varphi_{0}+\delta_{0}+\varphi_{1}(k)+a_{0}\right) \\
\dot{y_{O_{4}}}(k)=\dot{y_{O_{3}}}(k)+S \omega \cos \left(\varphi_{0}+\delta_{0}+\varphi_{1}(k)+a_{0}\right)
\end{array},(k=1, \ldots, n)\right.
$$

\section{Trajectory analysis and parameter determination of the seedling pick-up mechanism}

\subsection{Analysis of the influence of transmission ratio on the seedling picking trajectory}

The periodic twice unequal amplitude total transmission ratio function is defined through the cubic non-uniform B-spline curve fitting method. In this study, 20 type value points are selected in a cycle $q_{\mathrm{j}}\left(\phi_{\mathrm{j}}, i_{\mathrm{j}}\right)$, where $j=1,2 \ldots 20 ; \phi_{\mathrm{j}}$ is the angle of the planetary carrier corresponding to the jth type value point; and $i_{\mathrm{j}}$ is the total transmission ratio corresponding to the jth type value point. The parameters of mechanism $\left(a_{1}, a_{2}, \varphi_{0}, \delta_{0}, a_{0}, S\right)$ are respectively set as $(58,57,20,-43,4,197)$.

The curve of the transmission ratio is displayed in Figure 3, where "O" is the twice unequal amplitude total transmission ratio curve corresponding to the total transmission ratio type value point and " $\times$ " is the curve of the first-stage transmission ratio corresponding to the type value point of the first stage transmission ratio. The other one without the type value point is the secondary transmission ratio curve. Figure 3 shows that the peak values of the first (type value point $\phi_{1}-\phi_{9}$ ) and second peak intervals (type value point $\phi_{9}-\phi_{20}$ ) of the total transmission ratio curve are determined by type points 5 and 12, respectively. The other type value points are used as helping points to control the total transmission ratio curve.

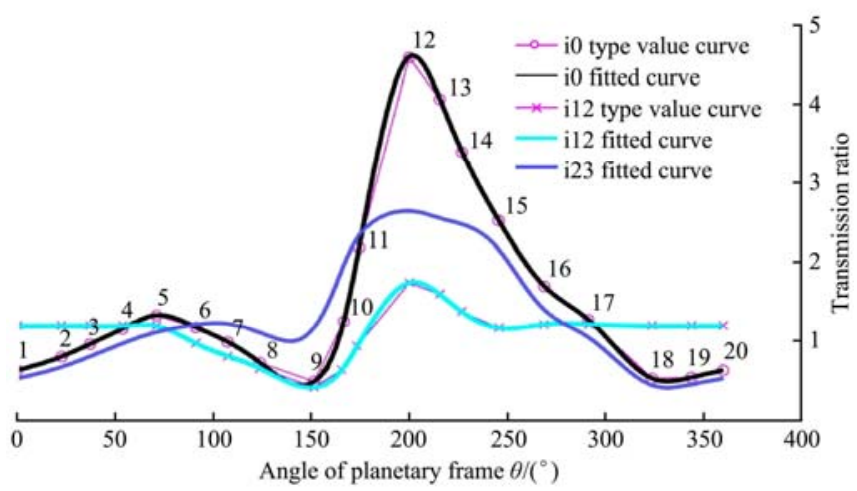

Figure 3 Transmission ratio curve

4.2 Influence of the ratio of the two amplitude fluctuations of the transmission ratio on the seedling path

As shown in Figure 3, the ordinate value of the points on the $\mathrm{i}_{0}$-type value curve (i.e., total transmission ratio curve) is unchanged, and the abscissa is adjusted to change the proportion of the two fluctuation processes during the period of rotation. Figure $4 \mathrm{~b}$ illustrates the change in the seedling track during the change in the total transmission ratio (type value points $\phi_{6}-\phi_{11}$ ) from $\mathrm{d} 1$ (91.3, $107.3,123.8,151.4,166.6,177.4)$ to $\mathrm{d} 2(86.3,97.7,113.4,141.4$ $156.6,164.4)$ and $\mathrm{d} 3(80.3,87.7,103.8,131.4,146.6,159.4)$. The ratio of the first peak interval of the total transmission ratio decreases during the period, the curve changes, and the change degree of the second peak interval of the total transmission ratio tends to be relatively flat.

Figure 4 a shows that as the type value point $\mathrm{d} 1$ change to $\mathrm{d} 3$, the abscissa of the transmission ratio curve and the transmission ratio trough shift to the left, the proportion of the first wave peak interval decreases, and the proportion of the second wave peak 
interval increases. However, the peaks of the two wave processes exhibit no obvious corresponding trajectories in Figure 4b, namely, $\mathrm{g} 1, \mathrm{~g} 2$, and $\mathrm{g} 3$ for $\mathrm{d} 1, \mathrm{~d} 2$, and $\mathrm{d} 3$, respectively, the twice unequal amplitude fluctuation ratio (i.e., the ratio between the first and second wave peaks) only affects the seedling pushing stage. The smaller the proportion of the first wave peak interval is, the smaller the relative angle of the seedling pushing stage. This condition is

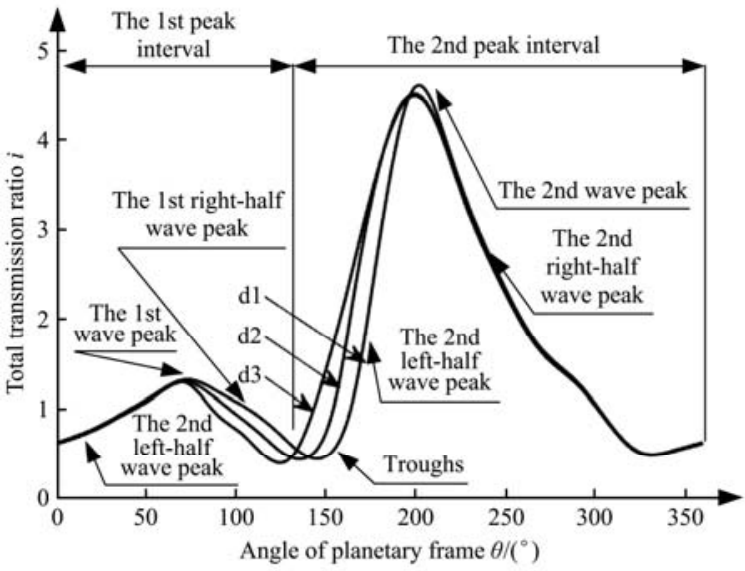

a. Analysis diagram of transmission ratios with different fluctuation ratios highly conducive to the formation of the seedling picking track with large depth and small overall track.

On the basis of the analysis of the trajectory of the man-machine interactive software (Figure 5), when the ratio of the first peak interval of the transmission ratio to the entire transmission ratio period is within the range of $0.4-0.5$, obtaining an enhanced trajectory of the potting section is easy.

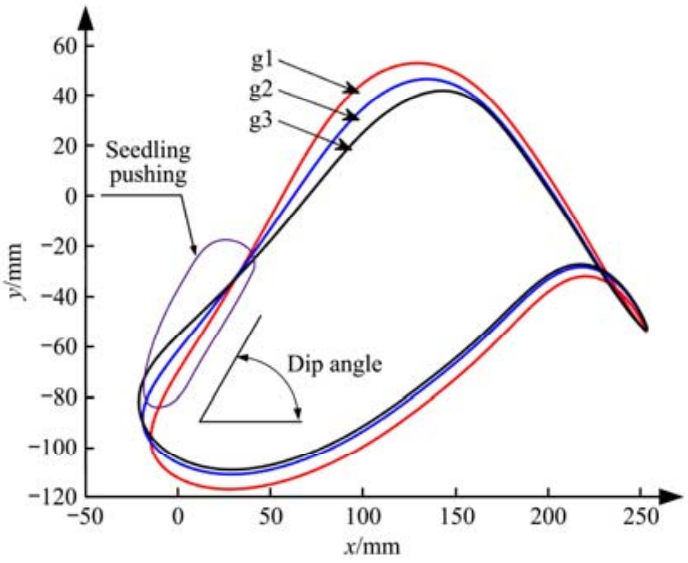

b. Analysis diagram of the track influence corresponding to the left shift of the d1-d3 abscissa

Figure 4 Analysis of the influences of the ratio of two amplitude fluctuations of the total transmission ratio on the seedling path AT Analysis and Optimization Software v1.0 Zhejiang University of science and technology
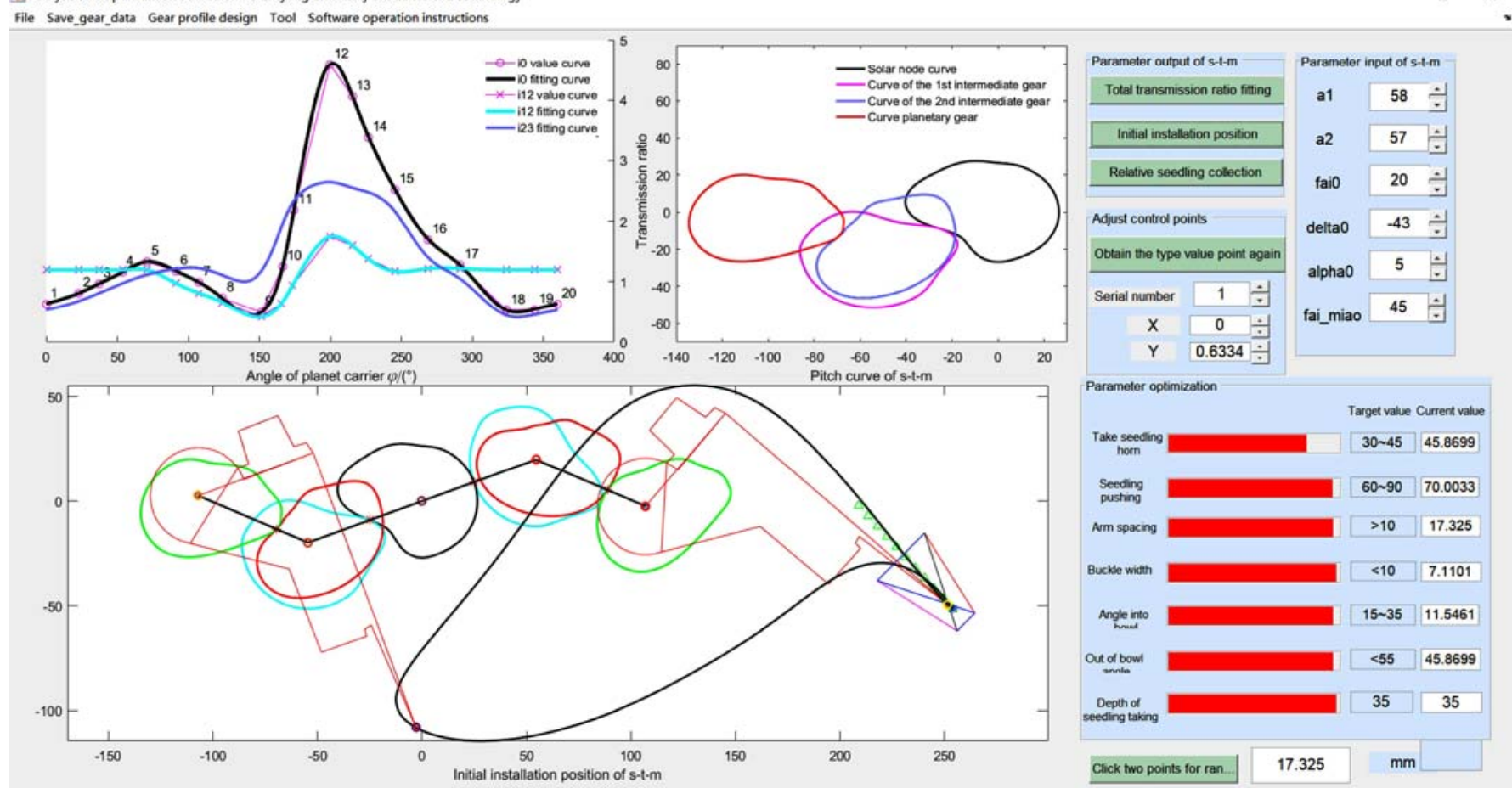

Figure 5 Human-computer interaction optimization software for the twice unequal amplitude seedling pick-up gear mechanism

\subsection{Analysis of the influence of the first peak interval of the} total transmission ratio on the seedling picking track

As shown in Figure 5, the change in the first peak interval of the transmission ratio is greatly affected by the values of $1,2,3,4$, 19, and 20. Figure 6a depicts the change in the seedling path when the type value points $\left(i_{1}, i_{2}, i_{3}, i_{4}, i_{19}, i_{20}\right)$ of the transmission ratio from $\mathrm{d} 1(0.633,0.805,0.964,1.154,0.543,0.633)$ change to $\mathrm{d} 2(0.733,1.001,1.135,1.254,0.593,0.733)$ and $\mathrm{d} 3(0.533,0.705$, $0.864,1.054,0.532,0.533)$. The amplitudes of the first and second wave processes are affected by the adjustment of the left half of the first peak interval $\left(i_{1}, i_{2}, i_{3}, i_{4}\right)$. The effect of the corresponding seedling picking and holding stage is relatively obvious, whereas the influence of the clamping and taking stage is even larger than the former (Figure 6b). The total transmission ratio of the first peak interval changes smoothly, which is conducive to the formation of a narrow pick-up trajectory and a small overall trajectory. The findings suggest that the influence of the first peak interval of the total transmission ratio on the trajectory of the potting section is substantial. Therefore, this interval is suitable for the fine adjustment necessary to form the trajectory that satisfies the requirements.

4.4 Analysis of the influence of the second peak interval of the total-transmission ratio on the seedling picking track

The human-computer interactive software shows that the track 
affected by the second peak interval of the total transmission ratio is affected by type points 13-18. Figure 7 illustrates the change in the seedling path when the type value points $\left(i_{13}, i_{14}, i_{15}, i_{16}, i_{17}, i_{18}\right)$ of the transmission ratio from $\mathrm{d} 1$ (4.061, 3.392, 2.521, 1.645, 1.273, $0.532)$ change to $\mathrm{d} 2(4.301,3.652,2.821,1.995,1.473,0.732)$ and d3 $(3.761,3.002,2.321,1.495,1.003,0.501)$.

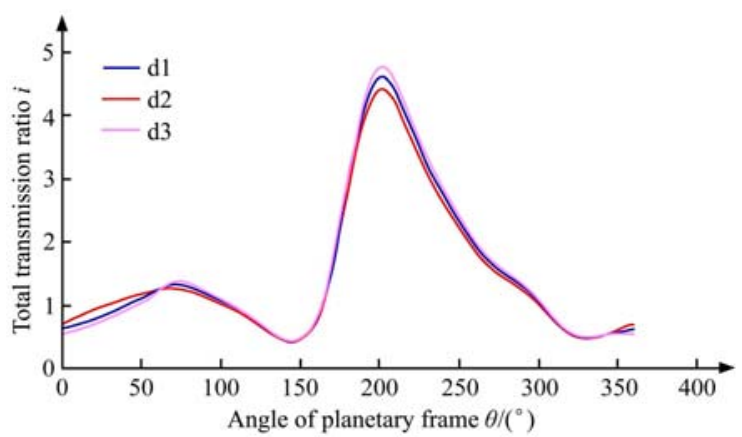

a. Analysis diagram of transmission ratios with different fluctuation ratios

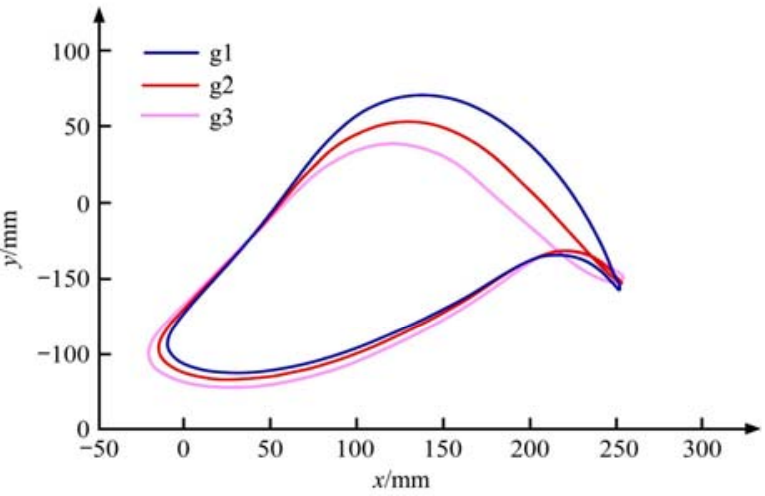

b. Analysis diagram of the track influence corresponding to type value points d1-d3

Figure 6 Analysis of the influence of the first peak interval of the total transmission ratio on the seedling picking track

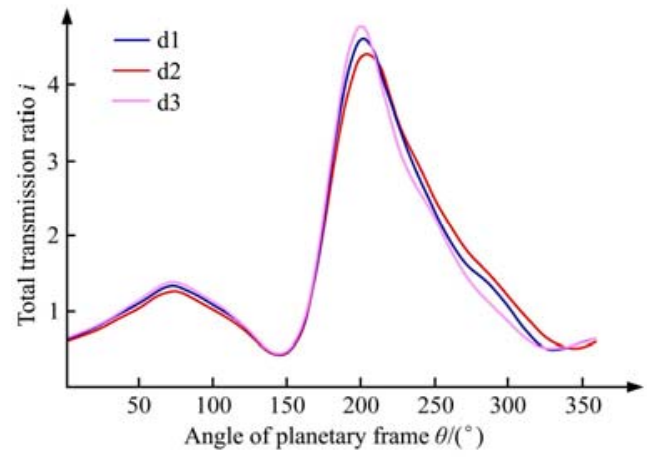

a. Analysis diagram of transmission ratios with different fluctuation ratios

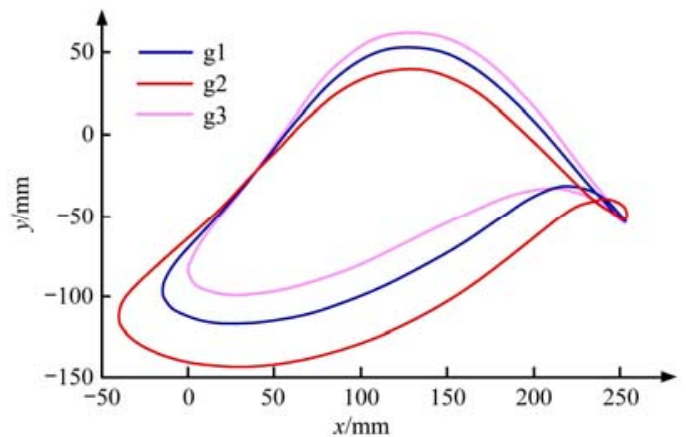

b. Analysis diagram of the track influence corresponding to type value points $\mathrm{d} 1-\mathrm{d} 3$ of the second wave peak influence

Figure 7 Analysis of the influence of the second peak range of the total transmission ratio on the seedling picking track
The comparison of Figures $7 \mathrm{a}$ and $6 \mathrm{a}$ shows that when the right half of the second peak interval $\left(i_{13}, i_{14}, i_{15}, i_{16}, i_{17}, i_{18}\right)$ is adjusted, the influence of the fitting method will also affect the entire fitting curve. However, the influence on the non-adjusted region is not greater than that on the left half of the first wave peak; only the influence on the amplitude of the second wave peak interval is large. The effect on the amplitude of the first wave peak interval is small, and the amplitude increases with the decrease in the adjusted value.

The comparison of Figures $7 \mathrm{~b}$ and $6 \mathrm{~b}$ indicates that adjusting the right half of the second wave peak interval can significantly enlarge or reduce the track stage in proportion. Figure 7a shows that the right half of the second wave peak interval greatly influences the overall tracking size and buckle width. Therefore, to obtain a small overall track with a long and thin cusp, the ordinate coordinates of the type point of the second wave peak interval should be minimized on the premise of ensuring the smooth curve.

\subsection{Analysis of the influence of the amplitude ratio of the two} waves on the seedling picking track

The two amplitudes of the total transmission ratio are determined using type value points 5 and 12. Figure 8 shows the change in the $(1.327,4.587),(1.174,5.587)$, and $(1.527,4.287)$ trajectories taken from the ordinates $i_{5}$ and $i_{12}$ of the two type value points, respectively.

Figure $8 \mathrm{a}$ shows that the peak fluctuation of the second wave peak interval is large, whereas that of the first wave peak interval is small. The adjustment of the amplitude ratio has an extremely small effect on the overall trajectory (Figure 8b). Therefore, the adjustment of the amplitude ratio applies to the small-scale fine adjustment after the determination of the shape of the overall trajectory.

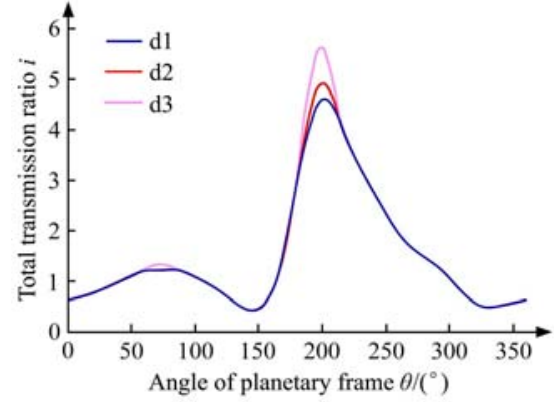

a. Analysis diagram of transmission ratios with different fluctuation ratios

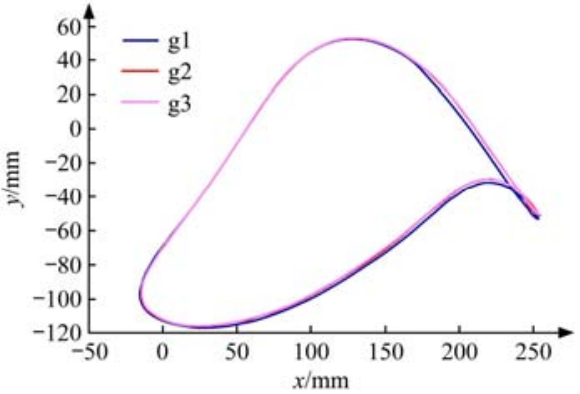

b. Analysis diagram of the track influence corresponding to the change in the ordinates of type value points 5 and 12

Figure 8 Analysis of the influence of the fluctuation ratio of the two amplitudes of the total transmission ratio on the track

4.6 Influence of mechanism parameters on the seedling picking track

To avoid reopening the shell of the picking arm in the later stage and save processing cost, the length $\mathrm{S}$ of the picking arm is set to a constant value of $152 \mathrm{~mm}$. $L$, which represents the distance between the centers of the central and planetary axes, is 
determined as $L=\left(a_{1}+a_{2}\right) / \cos \left(\delta_{0} / 2\right)$, The influence of the change in $L / S$ on the trajectory is analyzed. As shown in Figure 9, the seedling path increases with the increase in $L$ at a certain proportion. The ring buckle changes from large to small with the increase of $L$ until it disappears. Given that the ideal $L / S$ structure parameter of the seedling pick-up mechanism should be less than 1 , selecting the parameter value within $0.7-1.0$ is appropriate.

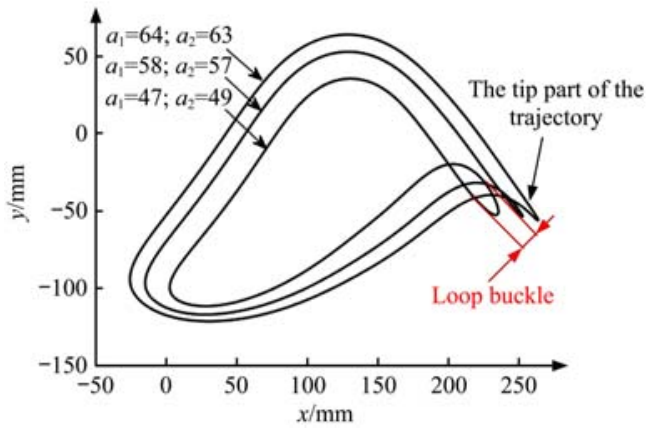

Figure 9 Analysis of the influence of $L / S$ ratio on the seedling picking track

The effects of $\varphi_{0}, \delta_{0}$, and $\alpha_{0}$ on the trajectory are also investigated. When $\delta_{0}=-43^{\circ}$ and $\alpha_{0}=4^{\circ}, \varphi_{0}$ is set to $10^{\circ}, 20^{\circ}$, and $30^{\circ}$ as shown in Figure 10. When $\varphi_{0}=20^{\circ}$ and $\alpha_{0}=4^{\circ}, \delta_{0}$ is set to $-33^{\circ},-43^{\circ}$, and $-53^{\circ}$ as shown in Figure 11. When $\varphi_{0}=20^{\circ}$ and $\delta_{0}=-43^{\circ}, \alpha_{0}$ is set to $-4^{\circ}, 4^{\circ}$, and $14^{\circ}$ as shown in Figure 12 . Table 2 lists the change process.

Table 2 implies that the change in $\varphi_{0}, \delta_{0}$, and $\alpha_{0}$ significantly affect the seedling angle (the angle between the seedling needle and the seedling tray is affected by the overall trajectory angle), seedling pushing angle, and buckle width. By utilizing expert experience and considering the large influence of the distance among the seedling arms on the seedling picking trajectory, the seedling picking angle, seedling pushing angle, buckle width, and seedling picking are selected as the four indexes of arm spacing to describe the significance of the parameter influence. Table 3 presents the simulation results. The results shown in Figures 10a-10c and Table 4 suggested that the four indexes are affected by $\varphi_{0}, \delta_{0}$, and $\alpha_{0}$.

Table 4 shows that the width of the sharp mouth and the distance among the picking arms are not affected by $\varphi_{0}$. The influence relationship among the seedling pushing angles is unclear. In addition, $\alpha_{0}$ does not affect the width of the sharp mouth of the picking trajectory, and $\delta_{0}$ exerts an influence on the four indexes of the picking trajectory.

Table 2 Effects of the changes in $\varphi_{0}, \delta_{0}$, and $\alpha_{0}$ on the seedling path

\begin{tabular}{|c|c|c|c|c|}
\hline Invariant factor & Change factor & Value & Influence of trajectory & Value \\
\hline $\begin{aligned} \delta_{0} & =-43^{\circ} \\
\alpha_{0} & =4^{\circ}\end{aligned}$ & $\varphi_{0}$ & $\begin{array}{l}10^{\circ} \\
20^{\circ} \\
30^{\circ}\end{array}$ & $\begin{array}{l}\text { If } \varphi_{0} \text { is changed, the shape of the track will not be affected, but the } \\
\text { inclination of the overall track will be. }\end{array}$ & $\begin{array}{l}\text { For the seedling box with an inclination of } \\
40^{\circ}-60^{\circ} \text {, initial installation angle }=20^{\circ}\end{array}$ \\
\hline $\begin{aligned} \varphi_{0} & =20^{\circ} \\
\alpha_{0} & =4^{\circ}\end{aligned}$ & $\delta_{0}$ & $\begin{array}{l}-33^{\circ} \\
-43^{\circ} \\
-53^{\circ}\end{array}$ & $\begin{array}{l}\text { As } \delta_{0} \text { decreases, the sharp angle between the overall trajectory and the } \\
\text { horizontal plane decreases, the width of the buckle increases, and the angle } \\
\text { of the seedling pushing increases. }\end{array}$ & The value of $\delta_{0}$ is generally $-43^{\circ}$ \\
\hline $\begin{aligned} \varphi_{0} & =20^{\circ} \\
\delta_{0} & =-43^{\circ}\end{aligned}$ & $\alpha_{0}$ & $-4^{\circ}$ & $\begin{array}{l}\text { As } \alpha_{0} \text { decreases, the sharp angle between the overall trajectory and the } \\
\text { horizontal plane decreases, the width of the buckle increases, and the angle of } \\
\text { the seedling pushing increases. }\end{array}$ & The value of $\alpha_{0}$ is generally $-4^{\circ}$ \\
\hline
\end{tabular}

Table 3 Numerical simulation results

\begin{tabular}{|c|c|c|c|c|c|c|c|}
\hline Group number & $\varphi_{0} /{ }^{\circ}$ & $\delta_{0} /{ }^{\circ}$ & $\alpha_{0} /{ }^{\circ}$ & Seedling picking angle $/\left(^{\circ}\right)$ & Seedling pushing angle $/\left(^{\circ}\right)$ & Tip width/mm & Distance among seedling arms $/ \mathrm{mm}$ \\
\hline 1 & 10 & -43 & 4 & 58.07 & 64.24 & 6.92 & 17.395 \\
\hline 2 & 20 & -43 & 4 & 46.71 & 70.17 & 6.92 & 17.395 \\
\hline 4 & 20 & -33 & 4 & 37.03 & 63.92 & 10.14 & 23.44 \\
\hline 5 & 20 & -53 & 4 & 56.22 & 70.94 & 9.51 & 9.79 \\
\hline 6 & 20 & -43 & 14 & 38.63 & 63.99 & 10.28 & 16.63 \\
\hline
\end{tabular}

Table 4 Influences of $\varphi_{0}, \delta_{0}$, and $\alpha_{0}$ on the four indexes of seedling path

\begin{tabular}{cccc}
\hline & Variation of the seedling angle & Variation of the seedling pushing angle & Variation of the tip width \\
\hline$\Delta \varphi_{0}=10^{\circ}$ & $10.92^{\circ}$ & Vnclear influence relationship & Not affected by $\varphi_{0}$ \\
$\Delta \delta_{0}=20^{\circ}$ & $19.19^{\circ}$ & $7.02^{\circ}$ & $0.63 \mathrm{~mm}$ \\
$\Delta \alpha_{0}=18^{\circ}$ & $14.73^{\circ}$ & $7.22^{\circ}$ & Not affected by $\varphi_{0}$ \\
\hline
\end{tabular}

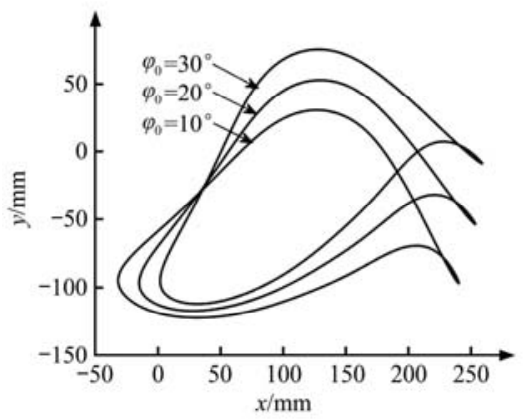

a. Influence of $\varphi_{0}$ on the seedling track

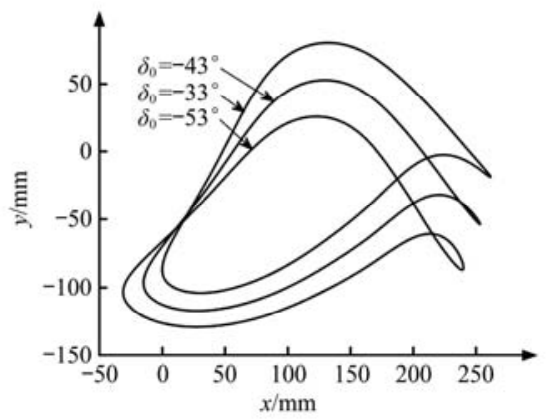

b. Influence of $\delta_{0}$ on the seedling track

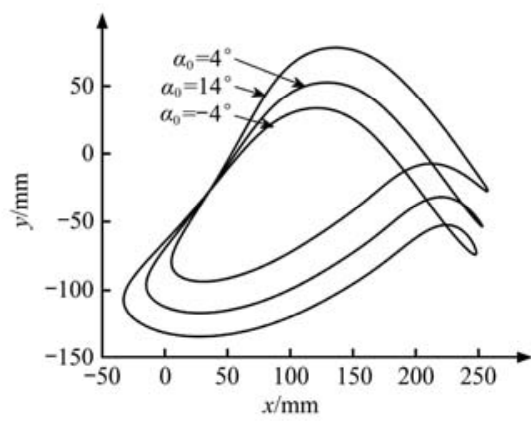

c. Influence of $\alpha_{0}$ on the seedling track

Figure 10 Influences of the parameters of the seedling taking mechanism on the seedling track 
4.7 Analysis of the parameters of the seedling pick-up mechanism

On the basis of the existing local and foreign studies and achievements of the current research group ${ }^{[27-32]}$, This study proposes reasonable kinematic design requirements for the seedling taking mechanism (Table 5).

The type value points of the total transmission ratio are continuously adjusted in accordance with the design requirements of the seedling pick-up mechanism, influence of the mechanism parameters on the seedling picking track, and human-computer interaction software developed by the author until a group of non-inferior solutions of parameters for the planetary gear train seedling pick-up mechanism are obtained $\left(a_{1}=58 \mathrm{~mm}, a_{2}=57 \mathrm{~mm}\right.$, $\varphi_{0}=20^{\circ}$, and $\delta_{0}=4^{\circ}$ ). The corresponding design of the seedling pick-up mechanism is shown in Table 5. The velocity curves in the $\mathrm{x}$ - and $\mathrm{y}$-directions and the resultant velocity of needle point $\mathrm{O}_{4}$ of the seedling claw are displayed in Figures 11a-11c, respectively.

Table 5 Optimization objectives and results

\begin{tabular}{lcc}
\hline \multicolumn{1}{c}{ Name } & Optimization objective & $\begin{array}{c}\text { Optimization } \\
\text { result }\end{array}$ \\
\hline Seedling picking angle $/\left(^{\circ}\right)$ & $35-50$ & 46.71 \\
Seedling pushing angle $/\left(^{\circ}\right)$ & $60-90$ & 70.17 \\
Distance among seedling arms $/ \mathrm{mm}$ & $>5$ & 17.395 \\
Tip width/mm & $<10$ & 6.92 \\
Bowling angle $/\left(^{\circ}\right)$ & $10-30$ & 11.94 \\
Bowling angle $/\left(^{\circ}\right)$ & $<55$ & 46.71 \\
Picking depth $/ \mathrm{mm}$ & 35 & 35 \\
Gear modulus $/ \mathrm{mm}$ & $>2$ & 2 \\
\hline
\end{tabular}

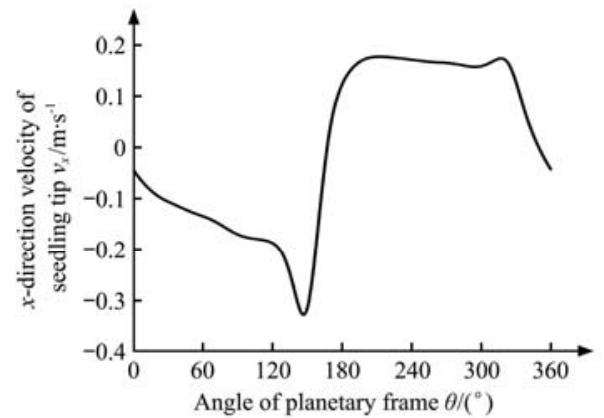

a. Velocity curve in $x$-direction

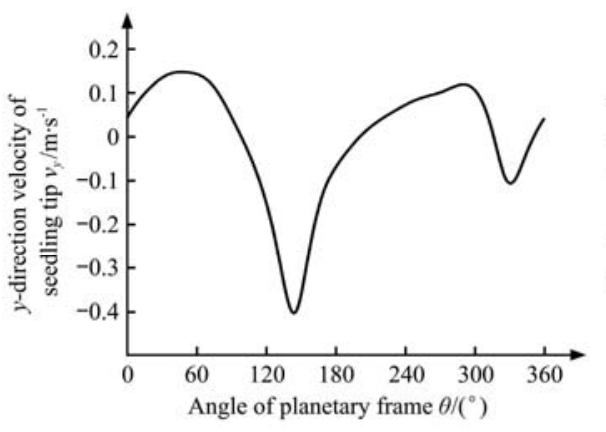

b. Velocity curve in $y$-direction

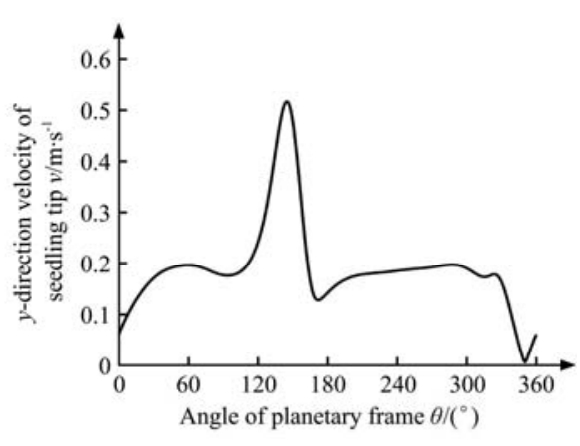

c. Resultant velocity curve

Figure 11 Velocity curve of the needle point of the seedling arm

\section{Simulation analysis of the seedling pick-up mechanism}

Adams software is used to simulate the seedling pick-up mechanism. The velocity curves in the $x$ - and $y$-directions and the resultant velocity of the seedling tip (Figures 12a-12c, respectively) are compared with those obtained from the theoretical analysis (Figures 11a-11c, respectively). The result reveals that the curves in the two figures are consistent with each other. The reasons for the jitter in ADAMS simulation curve are as follows: 1) in the virtual prototype model, spring force is added between the clearance eliminating fork and the box, and between the seedling pushing rod and the seedling picking arm, and certain initial force

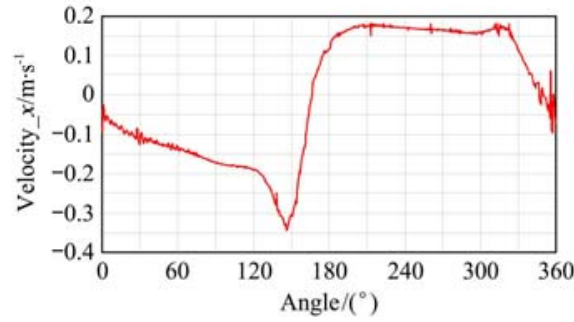

a. Velocity curve in $x$-direction

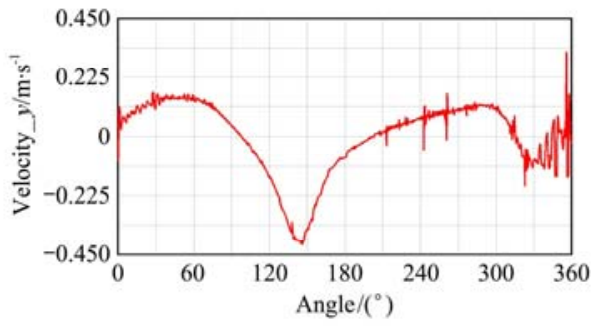

b. Velocity curve in $y$-direction is set, which leads to local shaking in the whole rotation process; 2) all gear pairs and the cam and fork of the seedling picking arm are added with contact constraints, which will produce friction resistance between them, resulting in small vibration.

\section{Experiment of the seedling pick-up mechanism}

\subsection{Comparison and analysis of the seedling paths of the seedling pick-up mechanism}

The seedling picking track of the idling experiment is shown in Figure 13c. The finding shows that the trajectory of the experimental track is consistent with those of the theoretical (Figure 13a) and simulated seedling picking tracks (Figure 13b).

Figure 12 Simulation velocity curve of the needle point of seedling picking arm

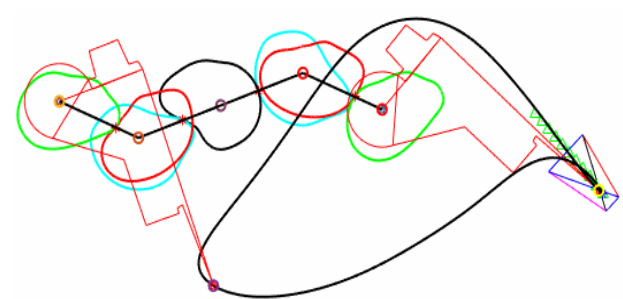

a. Theoretical track

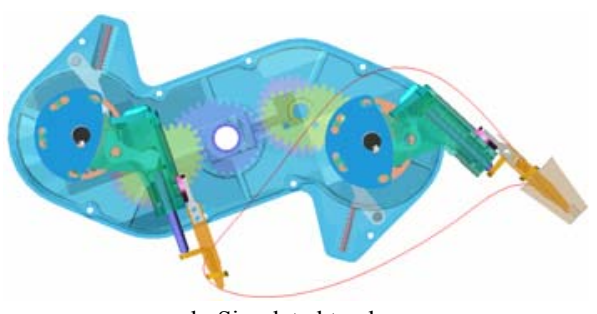

b. Simulated track

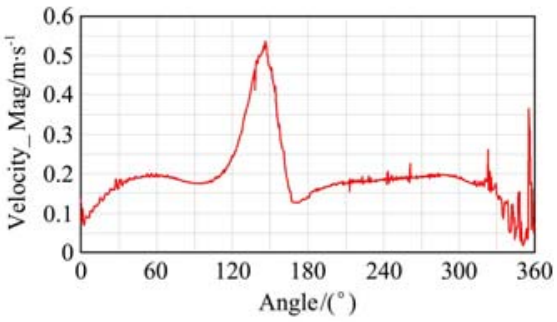

c. Resultant velocity curve

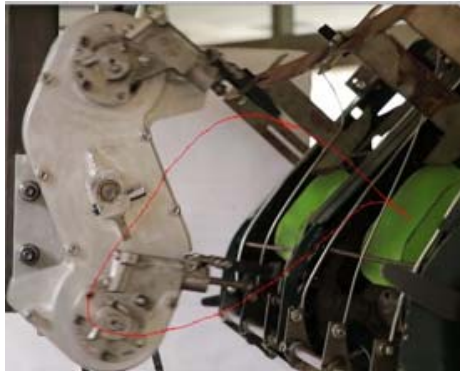

c. Trail of the seedling collection experiment

Figure 13 Trajectory of the seedling pick-up mechanism 


\subsection{Analysis of the experimental results of seedling collection} by using the seedling collection mechanism

The idling experiment confirms the feasibility and consistency of the proposed mechanism with the theoretical design. To verify the applicability of the proposed mechanism, the seedling picking experiment of broccoli potted seedlings was performed.

Figures 14a-14c depict the experimental conditions of the seedling picking, holding, and pushing, processes. Table 6 indicates that when the rotation speeds of the seedling pick-up mechanism are $40 \mathrm{r} / \mathrm{min}, 50 \mathrm{r} / \mathrm{min}$, and $60 \mathrm{r} / \mathrm{min}$, the success rates of the seedling picking exceeds are $95.7 \%, 96.9 \%, 97.3 \%$.
As the rotation speed increases, the qualified rate of the substrate decreases and the number of damaged plants increases. The low qualified rate of the substrate can be attributed to three main reasons: (1) the vibration of the seedlings during transportation causes them to not fit the bowl plate; (2) the growth of the mixed order of the leaves of the bowl seedlings causes the leaves to get stuck in the gap between the pushing claw and the shell of the picking arm during the clamping stage, and the entrainment and the stems and leaves of the bowl seedlings intertwine; (3) part of the bowl seedlings drop from the bowl plate due to vibration.

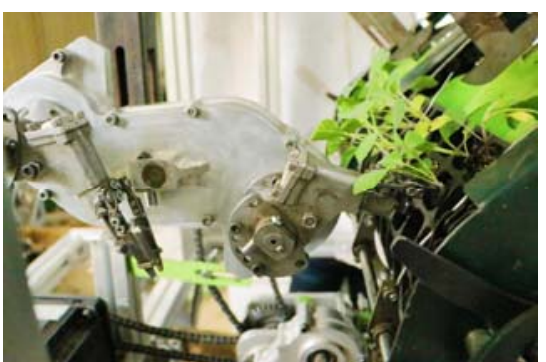

a. Seedling picking

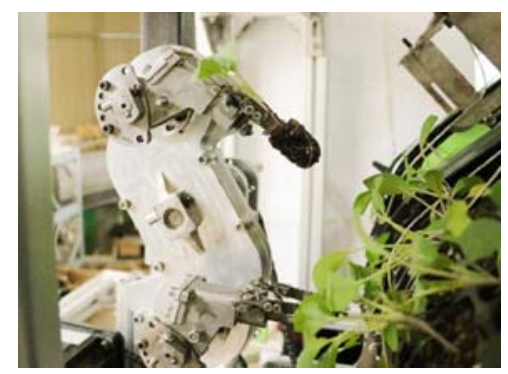

b. Seedling holding

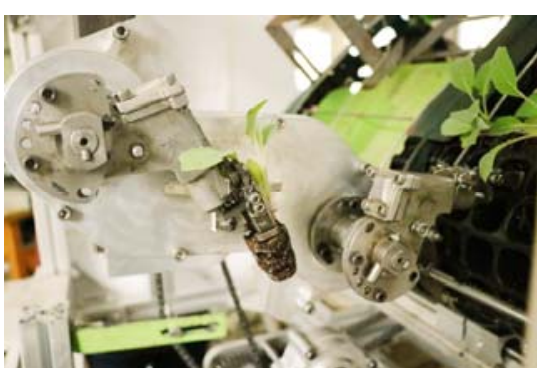

c. Seedling pushing

Figure 14 Experimental process of broccoli seedling

Table 6 Results of the potted broccoli seedling collection experiment

\begin{tabular}{|c|c|c|c|c|c|c|c|c|}
\hline $\mathrm{Speed} / \mathrm{r} \cdot \min ^{-1}$ & $\begin{array}{l}\text { Seedling } \\
\text { success }\end{array}$ & $\begin{array}{l}\text { Seedling } \\
\text { failure }\end{array}$ & $\begin{array}{l}\text { Total number of } \\
\text { seedlings taken }\end{array}$ & $\begin{array}{c}\text { Success rate of } \\
\text { seedling collection }\end{array}$ & $\begin{array}{l}\text { Slight matrix } \\
\text { damage }\end{array}$ & $\begin{array}{l}\text { Medium matrix } \\
\text { damage }\end{array}$ & $\begin{array}{c}\text { Serious matrix } \\
\text { damage }\end{array}$ & $\begin{array}{c}\text { Matrix } \\
\text { qualification rate }\end{array}$ \\
\hline 40 & 22 & 1 & 23 & 95.7 & 19 & 4 & 0 & 81.80 \\
\hline 50 & 31 & 1 & 32 & 96.9 & 26 & 5 & 1 & 81.25 \\
\hline 60 & 72 & 2 & 74 & 97.3 & 56 & 15 & 3 & 75.70 \\
\hline
\end{tabular}

\section{Conclusions}

In this study, a design method for obtaining the optimal seedling taking track was proposed by adjusting the total transmission ratio curve via human-computer interaction. A planetary non-circular gear seedling pick-up mechanism that can realize the twice unequal amplitude transmission ratio was designed. The kinematics model of the proposed mechanism is established by distributing the first and second transmission ratios and controlling and solving the pitch curve shape of the non-circular gear. The human-computer interactive optimization software was developed, and a group of non-inferior solution parameters for the seedling pick-up mechanism was determined through expert experience and the influence of the parameters of the seedling pick-up mechanism on the trajectory. The virtual prototype simulation experiment of the seedling pick-up mechanism was performed using Adams software, and the corresponding simulation track was obtained. The idling test of the seedling pick-up mechanism was conducted via high-speed camera technology to determine the experimental track. After comparing the idling experimental tracks, the results reveal that the theoretical, experimental, and simulated trajectories are the same. The results of the seedling picking experiment show that when the rotation speeds of the seedling pick-up mechanism are $40 \mathrm{r} / \mathrm{min}$, $50 \mathrm{r} / \mathrm{min}$, and $60 \mathrm{r} / \mathrm{min}$, the success rates of the seedling picking exceeds are $95.7 \%, 96.9 \%, 97.3 \%$. Moreover, the qualified rate of the matrix decreased and the number of damaged plants increased with the increase of rotating speed.

\section{Acknowledgements}

This work is supported by the National Natural Science
Foundation of China (Grant No. 52075497; No. 51775512), the National Key Research and Development Program of China (Grant No. 2017YFD0700800), the Key Research and Development Projects in Zhejiang Province (Grant No. 2018C02046).

\section{[References]}

[1] Zhou M L, Shan Y Y, Xue X L, Yin D Q. Theoretical analysis and development of a mechanism with punching device for transplanting potted vegetable seedlings. Int J Agric \& Biol Eng, 2020; 13(4): 85-92.

[2] Xue X L, Li L H, Xu C L, Li E Q, Wang Y J. Optimized design and experiment of a fully automated potted cotton seedling transplanting mechanism. Int J Agric \& Biol Eng, 2020; 13(4): 111-117.

[3] Ji J T, Cheng Q, Jin X, Zhang Z H, Xie X L, Li M Y. Design and test of 2ZLX-2 transplanting machine for oil peony. Int J Agric \& Biol Eng, 2020; 13(4): 61-69.

[4] Jin X, Cheng Q, Zhao B, Ji J T, Li M Y. Design and test of 2ZYM-2 potted vegetable seedlings transplanting machine. Int J Agric \& Biol Eng, 2020; 13(1): 101-110.

[5] Zhou M L, Hua Z Y, Wang J Y, Wang L, Zhao Y, Yin D Q. New type of transverse moving box mechanism for pot seedling transplanting machine. Int J Agric \& Biol Eng, 2018; 11(2): 70-75.

[6] Choi W C, Kim D C, Ryu I H, Kim K U. Development of a seedling pick-up device for vegetable transplanters. Transactions of the ASAE, 2002; 45(1): 13-19.

[7] Pandirwar A, Kumar A, Mani I, Bhowmik A. Development and Evaluation of Semi-Automatic Six Row Onion Seedlings Transplanter. Agricultural Mechanization in Asia, Africa \& Latin America, 2019; 50(1): 29-35.

[8] Iqbal M Z. Design of a gear driven hopper type dibbling mechanism for a $2.7 \mathrm{~kW}$ two-row pepper transplanter. Master dissertation, Chungnam National University, Daejeon, Korea, 2019; 64p.

[9] Tsuga K. Development of fully automatic vegetable transplanter. Japan Agricultural Research Quarterly, 2000; 34(1): 21-28.

[10] Shaw L N. Automatic transplanter for vegetables. Proceedings of Florida State Horticultural Society, 1997; 110: 262-263.

[11] Shaw L N. Removing and handling modular vegetable seedlings from nursery trays. Proceedings of Florida State Horticultural Society, 1999; 
112: $153-155$.

[12] Kang T G, Kim S W, Kim Y, Keun, L S, Hee J, Hyeon J. Analysis of pick-up mechanism for automatic transplanter. Journal of Agriculture \& Life Science, 2017; 51(1): 187-192.

[13] Thomas E V. Development of a mechanism for transplanting rice seedlings. Mechanism and Machine Theory, 2002, 37(4): 395-410.

[14] Kumar G V P, Raheman H. Development of a walk-behind type hand tractor powered vegetable transplanter for paper pot seedlings. Biosystems Engineering, 2011, 110(2): 189-197.

[15] Xin L, Lv Z J, Wang W Q, Zhou M L, Zhao Y. Optimal design and development of a double-crank potted rice seedling transplanting mechanism. Transactions of the ASABE, 2017; 60(1): 31-40.

[16] Han L H, Mao H P, Hu J P, Tian K P. Development of a doorframe-typed swinging seedling pick-up device for automatic field transplantation. Spanish Journal of Agricultural Research, 2015; 13(2): e0210. doi: 10.5424/sjar/2015132-6992.

[17] [17] Yu X X, Zhao Y, Chen B C, Zhou M L, Zhang H, Zhang Z C. Current situation and prospect of transplanter. Transactions of the CSAM, 2014; 45(8): 44-53. (in Chinese)

[18] Tian K P, Mao H P, Hu J P, Han L H, Miao X H, He J Y. Design and experimental study on gate shaped seedling taking device of automatic transplanter. Agricultural Mechanization Research, 2014; 36(2): 168-172. (in Chinese)

[19] Yin D Q, Wang J Z, Zhou M L, Yang Y C, Wang J W. Optimized design and experiment of seedling taking mechanism of bowl vegetable seedlings. Acta Agricultural Machinery, 2019; 50 (10): 64-71. (in Chinese)

[20] Dang Y G, Jin X, Li H J, Wang J, Lu Y B, Ding B W, et al. Design of a single degree of freedom four link mechanical arm for taking and throwing seedlings. Acta Agricultural Engineering, 2019; 35 (14): 39-47. (in Chinese)

[21] Liu Y, Mao H P, Han L H, Xu J Y, Ma G X, Li Y X. Micro CT based damage detection and parameter optimization of cucumber seedling lumps. Journal of Agricultural Engineering, 2018; 34 (12): 27-34. (in Chinese)

[22] Yuan T, Wang D, Wen Y S, Zhu S S, Chen Y, Tan Y Z. Design and experiment of air blowing vibration compound seedling taking mechanism of vegetable transplanter. Acta Agricultural Machinery, 2019; 50(10): 80-87. (in Chinese)

[23] Jia B Q, Ye M D, Zhai X N, Han L H, Lv J Q. Design and experiment of cam connecting rod combined seedling taking mechanism of vegetable transplanter. Agricultural Mechanization Research, 2019; 41(6): 78-82. (in Chinese)

[24] Yu G H, Yu J P, Tong J H, Ye B L, Zheng S Y. Design of a conjugate concave convex non-circular gear mechanism. China Mechanical Engineering, 2016; 27 (16): 2155-2159, 2165. (in Chinese)

[25] Yu Y X, Liu J K, Ye B L, Yu G H, Jin X J, Sun L, et al. Design and experimental research on seedling pick-up mechanism of planetary gear train with combined non-circular gear transmission. Chinese Journal of Mechanical Engineering, 2019; 49(32): 1-13

[26] Ye B L, Zeng G J, Deng B, Yang C L, Liu J K, Yu G H. Design and tests of a rotary plug seedling pick-up mechanism for vegetable automatic transplanter. Int J Agric \& Biol Eng, 2020; 13(3): 70-78

[27] Zhao X, Chen J N, Yang M X, Zhao Y. Seedling taking mechanism of two-stage free non-circular gear planetary potted seedling transplanter. Journal of Agricultural Machinery, 2014; 45(4): 123-127. (in Chinese)

[28] Yu G H, Yu T F, Ye B L, Hu H J, Wang L W. Design of a rotary plug seedling taking mechanism. Journal of Mechanical Engineering, 2015; 51(7): 67-76. (in Chinese)

[29] Yu G H, Yu T F, Ye B L, Jia D B, Wang L W, Hu H J. Research on a new type of planetary gear train mechanism. Journal of Mechanical Engineering, 2013; 49(15): 55-61. (in Chinese)

[30] Zhao X, Chen J N, Wang Y, Zhao Y, Li C L. Reverse design and analysis of "D-shaped" static track transplanting mechanism for rice seedlings. Acta Agricultural Engineering, 2012; 28(8): 92-97. (in Chinese)

[31] Wang M M, Song J N, Liu C L, Wang Y L, Sun Y P. Design and experiment of crank swing type seedling clamping mechanism of vegetable transplanter. Acta Agricultural Engineering, 2015; 31(14): 49-57. (in Chinese)

[32] Yu G H, Tong Z P, Sun L, Tong J H, Zhao X. Novel gear transmission mechanism with twice unequal amplitude transmission ratio. Journal of Mechanical Design, 2019; 141(9): 092304. doi: 10.1115/1.4043019. 